\title{
EDITORIAL Action needed on asthma plans
}

See linked articles by Sulaiman et al. on pg 161 and Ring et al. on pg 170

\section{*Helen K Reddel ${ }^{a}$ \\ a Woolcock Institute of Medical Research and University of Sydney, Sydney, Australia}

\section{*Correspondence:}

Associate Professor Helen K Reddel, Woolcock Institute of Medical Research, PO Box M77,

Missenden Rd Post Office, NSW 2050,

Australia

Tel: +61291140437

Fax: +61291140014

E-mail: hkr@med.usyd.edu.au

Commissioned article Not externally peer-reviewed Accepted 12th May 2011

Online 20th May 2011
Changing health-related behaviour, whether of patients or of health professionals, is an ongoing challenge. In the past 20 years there has been increasing emphasis on the rigorous evaluation of evidence for incorporation into clinical practice guidelines. However, there has also been emerging awareness that even rigorously-developed guidelines may fail to be adopted or implemented in the community.

Written asthma action plans, the subject of two papers in this issue of the Primary Care Respiratory Journal $(P C R J)$, are a good example of an intervention for which there is wellestablished evidence of effectiveness $s^{1,2}$ and strong recommendations in guidelines - but ongoing poor uptake. Action plans are relevant to all people with asthma, since exacerbations can be experienced even in mild or well-controlled disease; but multiple studies have found that they are owned by only a small minority of people with asthma.

The study by Sulaiman and colleagues ${ }^{3}$ provides confirmation of low rates of ownership or use of action plans in Melbourne, Australia. Amongst 225 adult participants, only 37\% reported having an action plan. The only independent predictor was a history of "spontaneous" shortness of breath, perhaps indicating patients with unidentified symptom triggers. The authors' qualitative research identified ambivalence by patients and GPs about the utility of action plans, consistent with earlier work on barriers and facilitators for their uptake. ${ }^{4,5}$ However, the fact that patients perceived action plans to be a marker of quality of medical care could be utilised to encourage GPs to provide more action plans. A higher rate of action plan ownership (47\%) was seen amongst the 75 children and adolescents, with feedback suggesting that administrative requests from school/kindergarten - perhaps prompted through the Asthma Friendly Schools program - may have been a contributory factor. Provision of financial incentives for health professionals to write action plans can also help to offset the time taken for this activity, but the success of such programs may be thwarted by burdensome paperwork. ${ }^{6}$

Research about enhancing the implementation of clinical practice guidelines has emphasised the need for clarity and simplicity in the wording of the guidelines.? The paper by Ring and colleagues ${ }^{8}$ identifies substantial confusion in terminology about asthma action plans, and suggests that this may contribute to poor uptake of action plans. Using a systematic model of linguistic analysis, the authors document the usage of terms relating to "asthma plans" in key publications, and trace the evolution of the usage and meaning of these terms. What emerges is an embarrassment of confusion - particularly in the usage of management or self-management plans, which sometimes refer to action plans, sometimes to the comprehensive program of management for an individual patient (medications, action plan, exercise, diet, management of co-morbidities etc), and sometimes to organisational systems for improving asthma care. Even within individual guideline documents a range of terms can be found, perhaps reflecting the incremental nature of guideline development and update. Confusion about such terminology, once established, can worsen with time, as writers unsure of which term to use may favour more generic terms such as "asthma plan". This issue is not mere pedantry, since guidelines are less likely to be implemented if they contain vague and non-specific recommendations.? Michie suggests that "rewriting guidelines to increase behavioural specificity may be the simplest, most effective method of increasing implementation". 9.

In response to their findings, Ring and colleagues propose a taxonomy for asthma plans, with the aim of reducing ambiguity and facilitating communication between health 


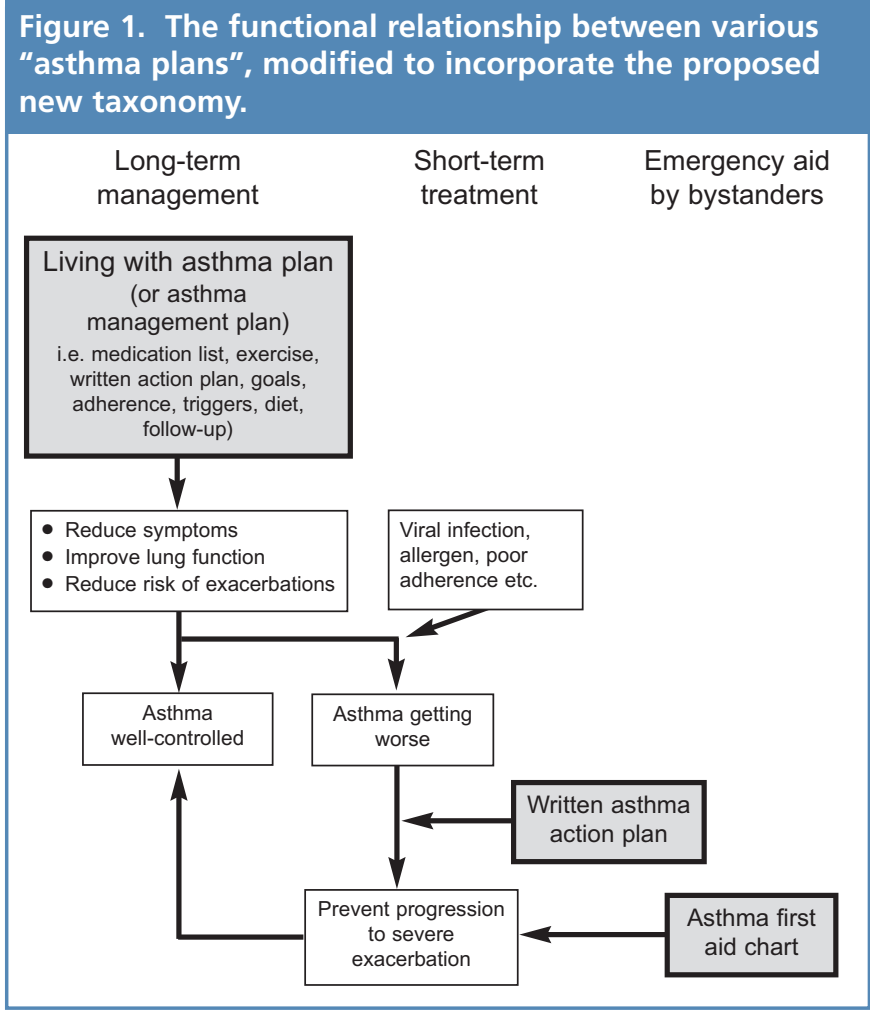

professionals and patients. Standardisation of terminology would also facilitate monitoring of uptake of action plans, by avoiding ambiguity in health survey questions. The authors propose three basic terms for patient-level plans - i.e. asthma medication plan, asthma action plan, and living with asthma plan - and for the organisational structure to support patient care, an asthma management system. The proposals appear sound, with the minor qualification that confusion could be further reduced by removing the word "plan" where it does not add meaning; "asthma medication plan", which is described as "a basic plan which at its simplest will be a list of prescribed medications" could be replaced simply by "list of asthma medications".

What strategies can be adopted to move this issue forward from discussion to implementation? The present publication, disseminated through the broad circulation of the PCRJ, will alert readers to the issue. However, deliberate and targeted action is needed in order to ensure that the recommendations are actually adopted. While journal correspondence may provide some feedback, broader agreement could be obtained through a brief plenary discussion at a major conference. The next step would be to obtain endorsement from an appropriate professional body - e.g. the International Primary Care Respiratory Group or the British Thoracic Society - and to use this endorsement as leverage to obtain buy-in from a broad range of relevant stakeholders (other professional organisations, guidelines bodies, consumer groups, health departments). A key strategy in any such approach would be to provide simple tools to facilitate use of the agreed terminology, including short text descriptions which could be used routinely with each term to clarify the intended meaning. For example, the Australian Centre for Asthma Monitoring recommends the following wording for health surveys: "Do you have a written asthma action plan, that is, written instructions of what to do if your asthma is worse or out of control?". ${ }^{10}$ Another potential tool is shown in Figure 1, a diagram which has been used in Australia to illustrate the functional relationships of various "asthma plan" terms; this may be a more effective visual mnemonic than a purely taxonomic figure.

Of course, there are other, more difficult barriers to overcome before ownership of written action plans can be substantially increased, particularly a lack of certainty for clinicians around what treatment changes to recommend, and when." There is a particular need for pragmatic studies to evaluate the effectiveness of increasing medications early in an exacerbation, and also for validation of simple criteria for when treatment should be changed. Harmonising the terminology around action plans is a first important step in avoiding confusion and monitoring of progress.

\section{Conflict of interests}

In the last 3 years, Helen Reddel has received research grants from GlaxoSmithKline (GSK), has participated on advisory boards for AstraZeneca (AZ), GSK and Novartis, has provided consulting for Biota, GSK and Novartis, and has spoken at symposia funded by AZ, Boehringer Ingelheim, Getz, GSK and Merck.

\section{References}

1. Gibson PG, Powell H, Coughlan J, et al. Self-management education and regular practitioner review for adults with asthma. Oxford: Update Software, The Cochrane Library, Issue 1, 2003.

2 Gibson PG, Powell $H$. Written action plans for asthma: an evidence-based review of the key components. Thorax 2004;59:94-9. http://dx.doi.org/ 10.1136/thorax.2003.011858

3 Sulaiman N, Aroni R, Thien F, et al. Written Asthma Action Plans (WAAPs) in Melbourne general practices: a sequential mixed methods study. Prim Care Resp J 2011;20(2):161-9 http://www.thepcrj.org/journ/view_article.php?article_id=778.

4 Douglass J, Aroni R, Goeman D, et al. A qualitative study of action plans for asthma. BMJ 2002;324:1003-05. http://dx.doi.org/10.1136/bmj.324.7344.1003

5 Haughney J, Barnes G, Partridge M, Cleland J. The Living \& Breathing Study: a study of patients' views of asthma and its treatment. Prim Care Respir J 2004; 13:28-35. http://dx.doi.org/10.1016/j.pcrj.2003.11.007

6 Zwar NA, Comino EJ, Hasan I, Harris MF, Primary Health Care Research. General practitioner views on barriers and facilitators to implementation of the Asthma 3+ Visit Plan. Med J Aust 2005;183:64-7.

7. Grol R, Dalhuijsen J, Thomas S, et al. Attributes of clinical guidelines that influence use of guidelines in general practice: observational study. BMJ 1998; 317:858-61.

8. Ring N, Pinnock $\mathrm{H}$, Wilson $\mathrm{C}$, et al. Understanding what asthma plans mean: a linguistic analysis of terminology used in published texts. Prim Care Respir J 2011;20(2):170-7 http://dx.doi.org/10.4104/pcrj.2011.00012

9 Michie S, Johnston M. Changing clinical behaviour by making guidelines specific. BMJ 2004;328:343-5. http://dx.doi.org/10.1136/bmj.328.7435.343

10 Australian Centre for Asthma Monitoring. 2007. Survey questions for monitoring national asthma indicators. Accessed: December 2007.

11 Reddel HK, Barnes DJ. Pharmacological strategies for self-management of asthma exacerbations. Eur Respir J 2006;28:182-99. http://dx.doi.org/ 10.1183/09031936.06.00105305 